Elsevier Editorial System(tm) for Biomedical Signal Processing and Control Manuscript Draft

Manuscript Number: BSPC-D-08-00104R1

Title: A Glucose-Insulin Pharmacodynamic Surface Modeling Validation and Comparison of Metabolic System Models

Article Type: Special Issue: IFAC 2008

Keywords: Pharmacodynamics; PD; Pharmacokinetics; PD; Metabolism; Diabetes; Insulin Sensitivity; Modeling; euglycaemic Clamp; Hyperinsulinaemic Clamp; Model Validation

Corresponding Author: Dr Geoffrey Chase, PhD

Corresponding Author's Institution:

First Author: Geoffrey Chase, PhD

Order of Authors: Geoffrey Chase, PhD; Steen Andreassen; Ulrike Pielmeier; Christopher E Hann; Kirsten A McAuley; J I Mann

Abstract: Metabolic system modeling for model-based glycaemic control is becoming increasingly important. Few metabolic system models are clinically validated for both fit to the data and prediction ability. This research introduces a new additional form of pharmaco-dynamic (PD) surface comparison for model analysis and validation. These 3D surfaces are developed for 3 clinically validated models and 1 model with an added saturation dynamic. The models include the well-known Minimal Model. They are fit to two different data sets of clinical PD data from hyperinsulinaemic clamp studies at euglycaemia and/or hyperglycaemia. The models are fit to the first data set to determine an optimal set of population parameters. The second data set is used to test trend prediction of the surface modeling as it represents a lower insulin sensitivity cohort and should thus require only scaling in these (or related) parameters to match this data set. This particular approach clearly highlights differences in modeling methods, and the model dynamics utilized that may not appear as clearly in other fitting or prediction validation methods. 


\title{
A Glucose-Insulin Pharmacodynamic Surface Modeling Validation and Comparison of Metabolic System Models
}

J. Geoffrey Chase*, Steen Andreassen.**, Ulrike Pielmeier**, Christopher E. Hann, * Kirsten A. McAuley*** and J. I. Mann***

* Mechanical Eng, Centre for Bio-Engineering, University of Canterbury, Christchurch, New Zealand

(Tel: +64-3-364-7001; e-mail: geoff.chase@Canterbury.ac.nz)

** Center for Model-based Medical Decision Support (MMDS), Aalborg University, Aalborg, Denmark(e-mail:sa@hst.aau.dk)

*** Edgar National Centre for Diabetes Research, University of Otago, School of Medicine, Dunedin, New Zealand (email: Kirsten.Mcauley@stonebow.otago.ac.nz)

\begin{abstract}
Metabolic system modeling for model-based glycaemic control is becoming increasingly important. Few metabolic system models are clinically validated for both fit to the data and prediction ability. This research introduces a new additional form of pharmaco-dynamic (PD) surface comparison for model analysis and validation. These 3D surfaces are developed for 3 clinically validated models and 1 model with an added saturation dynamic. The models include the well-known Minimal Model. They are fit to two different data sets of clinical PD data from hyperinsulinaemic clamp studies at euglycaemia and/or hyperglycaemia. The models are fit to the first data set to determine an optimal set of population parameters. The second data set is used to test trend prediction of the surface modeling as it represents a lower insulin sensitivity cohort and should thus require only scaling in these (or related) parameters to match this data set. This particular approach clearly highlights differences in modeling methods, and the model dynamics utilized that may not appear as clearly in other fitting or prediction validation methods.

Across all models saturation of insulin action is seen to be an important determinant of prediction and fit quality. In particular, the well reported under-modeling of insulin sensitivity in the Minimal Model can be seen in this context to be a result of a lack of saturation dynamics, which in turn affects its ability to detect differences between cohorts. The overall approach of examining PD surfaces is seen to be an effective means of analyzing and thus validating a metabolic model's inherent dynamics and basic trend prediction on a population level, but is not a replacement for data driven, patient-specific fit and prediction validation for clinical use. The overall method presented could be readily generalized to similar PD systems and therapeutics.
\end{abstract}

Keywords: Pharmacodynamics, Pharmacokinetics, Metabolism, Diabetes, Insulin Sensitivity, Modeling, euglycaemic Clamp, Hyperinsulinaemic Clamp, Model Validation. 


\subsection{INTRODUCTION}

Type 1 and Type 2 diabetes are epidemic [1-3] with significant economic cost [4-7], driven by the inability of individuals and their clinicians to achieve consistent adequate control of blood glucose levels [8-10]. Hence, the rate of costly chronic complications is rising. In addition, critical care and surgical studies have shown that successfully providing tight glycaemic control can significantly reduce mortality $[11-14]$ and cost $[15,16]$. However, achieving it has proven difficult, even though initial results show tighter control may be better [17, 18].

The potential of models for managing glycaemic levels in any insulin resistant cohort is thus of growing import. However, relatively few models have been clinically validated. For most models, the primary form of validation has been simple fitting of the model to match clinical data [19]. Occasionally, more rigorous prediction validation, which tests the models ability to predict the outcome of a known intervention on retrospective clinical data (or in a clinical trial) is used. However, only a few clinically validated models can predict within clinically acceptable ranges [20-26].

This paper presents a new form of model validation that examines the steady state pharmacodynamic (PD) surfaces, including underlying pharmaco-kinetics (PK). It is thus a means of analysing the fundamental model dynamics used over a range of input and response variables. Comparison to clinical data points on this surface can provide a means of validating the model's underlying dynamics.

In this research, a 3D surface of plasma insulin (x), plasma glucose (y) and resulting rate of change in endogenous glucose balance $(\mathrm{z})$ is compared to 77 sets of glycaemic clamp data from individuals with relatively high insulin sensitivity [20]. The resulting models are then assessed 
on a further 146 glycaemic clamps from a before-after intervention study of 73 normoglycaemic, high BMI $(\mathrm{BMI}>30)$ individuals [27] with relatively lower insulin sensitivity to determine whether the identified models and resulting PD surfaces can predict the new values by changes in insulin sensitivity. The overall approach is thus used to present and initially validate this new approach to metabolic system model validation in this comparison.

\subsection{METHODS}

\subsection{Models:}

Three clinically validated models are used in this analysis:

\section{Non-linear PK/PD Model (ND) \\ 2. Minimal Model (MM) \\ 3. Receptor Model (RM)}

The ND model has been used in several critical care studies [23, 28, 29], for insulin sensitivity testing and analysis $[25,30]$, and in prediction validation of a model for controlling type 1 diabetes [24]. The MM is well documented and used [31-37]. The RM model was developed for a Type 1 diabetes decision support system [20] and recently extended for critical care control $[26]$.

The dynamic system models (MM, ND) share the same basic PD formulation and can be jointly defined [25]. However, for clarity, the ND models are defined: 


$$
\dot{G}=-p_{G} G-S_{I} \frac{G}{1+\alpha_{G 2} G} \frac{Q}{1+\alpha_{G} Q}+\frac{P(t)}{V_{G}}+\frac{P_{\text {end }}}{V_{G}}
$$

where $G(t)[\mathrm{mmol} / \mathrm{L}]$ is the total plasma glucose, $Q(t)[\mathrm{mU} / \mathrm{L}]$ is the interstitial insulin concentration, which is assumed equal to plasma insulin concentration in this steady state analysis although other reasonable steady state ratios could be used equally well. Finally, $P(t)$ $[\mathrm{mmol} / \mathrm{min}]$ is exogenous carbohydrate appearance, $P_{\text {end }}[\mathrm{mmol} / \mathrm{min}]$ represents endogenous glucose appearance in a glucose distribution volume $V_{G}$. Patient endogenous glucose clearance and insulin sensitivity are $p_{G}[1 / \mathrm{min}]$ and $S_{I}$ [L/(mU.min)]. Michaelis-Menten function $\alpha_{G}$ $[\mathrm{L} / \mathrm{mU}]$ captures saturation of plasma insulin disappearance and glucose uptake by insulin, and $\alpha_{G 2}[\mathrm{~L} / \mathrm{mmol}]$ allows for the saturation of glucose-dependent glucose clearance.

The ND model thus has two forms. The first and extensively used form sets $\alpha_{G 2}=0$, saturating only the available insulin for action to remove glucose. The second, has non-zero values for both saturation terms $\alpha_{G 2}$ and $\alpha_{G}$. Thus, these variants (ND1 a sub-case of ND2) can be used to examine the need for saturating both the available insulin and the available glucose, in comparison to clinical clamp data over the PD surface. Thus, it can be determined if both saturation dynamics are required, or if saturating just available insulin sufficient.

The Minimal Model (MM) is thus effectively the case where: $P_{\text {end }}=\alpha_{G 2}=\alpha_{G}=0$. In addition, the term $-p_{G}{ }^{*} G$ is redefined as $-p_{G^{*}}\left(G-G_{E}\right)$, where $G_{E}$ is a basal glucose value not used in the ND model of Equation (1), but defined in the MM [33], and $S_{I}$ is the ratio of $\mathrm{p} 2$ and $\mathrm{p} 3$ that is used in the original and common MM formulations $[32,33]$. The MM model is thus defined here as:

$$
\dot{G}=-p_{G}\left(G-G_{E}\right)-S_{I} G Q+\frac{P(t)}{V_{G}}
$$


where $G(t)[\mathrm{mmol} / \mathrm{L}]$ is the plasma glucose level above an equilibrium or basal level $G_{E}$ $[\mathrm{mmol} / \mathrm{L}]$, and all other terms are as defined in Equation (1a). Equations (1a) and (1b) are numbered this way to highlight their similarity. In particular, as noted, there are several similarities between the ND1,2 and MM models. However, the PD surfaces are very different due to the differences in specific dynamics included, which this analysis and validation approach can highlight.

In this steady state PD surface analysis, $Q(t) \rightarrow Q_{s \mathrm{~s}}$ and $G(t) \rightarrow G_{S S}$ thus indicating steady state values, as found in glycaemic clamp testing to assess insulin sensitivity in vivo. Hence, the rate of change of glucose is (negatively equivalent) in Equations (1a,b) to the endogenous balance change for that input in the steady state $\left(\dot{G} \Leftrightarrow P_{s s}\right)$. Therefore, the glucose infusion required to maintain a glycaemic level in a glycaemic clamp test, at steady state, is assumed equivalent to the drop or change in glucose $(\dot{G})$, referred to here as change in the endogenous balance, that would result from the same steady state plasma and interstitial insulin $\left(Q_{s s}\right)$, and plasma glucose $\left(G_{s S}\right)$ values. Thus, the steady state ND and MM model pharmaco-dynamics based on glycaemic clamp test results can be ascertained using versions of Equations (1).

More specifically, the glucose infusion $P_{s s}$ in the clamp required to hold steady state glucose $G_{s s}$, at infusion resulting in steady state plasma insulin $I_{s s} \rightarrow Q_{s s}$, is equated to the potential rate of change (drop) in blood glucose if that infusion had not been given. Thus, it is a steady state approximation of the change in glucose at a given level of insulin and blood glucose (in steady state). The steady state assumption provides a unique surface for these dynamic models (ND, $\mathrm{MM}$ ) and relates this surface to readily available euglycaemic clamp data. 
The receptor model (RM) takes a different approach to modeling this system and is defined from a series of prior works as $[20,26]$ :

EndoBal $=$ Hepatic - Renal - P13 - P14

Hepatic $=-0.46 \mathrm{~min}^{-1} G-1.475 \mathrm{mmol} / \mathrm{min} / \mathrm{mU}_{S}+1.259 \mathrm{mmol} / \mathrm{L} / \mathrm{min} ; \quad G_{\max }=12.0 \mathrm{mmol} / \mathrm{L}$

Renal $=0.004 \mathrm{~L} / \mathrm{mmol} / \mathrm{min} G^{2}-0.064 \mathrm{~min}^{-1} G+0.278 \mathrm{mmol} / \mathrm{L} / \mathrm{min}$

$\mathbf{P 1 3}=0.56 \mathrm{~min}^{-1} * G /(G+1.5 \mathrm{mmol} / \mathrm{L})$

$\mathbf{P 1 4}=5.09 \mathrm{mmol} / \mathrm{L} / \mathrm{min} / \mathrm{mU} G^{*} I_{s} /(G+5.0 \mathrm{mmol} / \mathrm{L})$

$I_{s}=I^{*} 1 /\left((I-0.083 \mathrm{mU} / \mathrm{L})^{1.77}+(0.539 \mathrm{mU} / \mathrm{L})^{1.77}\right)^{(1 / 1.77)}$

where $G$ is the plasma glucose concentration, $I_{S}$ is the saturated or available plasma insulin, $I$. and all terms and values are as defined in $[20,26]$.

The RM is defined based on clinically observed gains/losses from the liver (Hepatic), and losses to the kidneys (Renal), insulin-dependent periphery (P14) and insulin-independent periphery (P13). Hence, this receptor based model is physiologically defined. Finally, $I_{s}$ is a saturated insulin effect for insulin-dependent uptake, and it should be noted that P13 is a saturable insulin independent uptake of glucose and P14 a saturable insulin dependent uptake. The other specific values were obtained by fitting to 77 clinical glycaemic clamp studies, so that this model is already identified for that original data set.

The net results of this model (EndoBal) creates the 3D PD surface used for this comparison. This term is equivalent to the change in endogenous balance as obtained from glycaemic clamp data $(\dot{G})$ defined previously for the dynamic models of Equations (1). The PD surface is thus mathematically defined for the MM and ND models, and a direct output of the RM model. Again, note that the RM model was created by directly fitting to clinical data, and thus needs no further alteration or analysis. 


\subsection{Clinical Data Sets:}

There are two sets of clinical data from glycaemic clamp studies. The first set covers 77 glycaemic clamp tests over 15 reported studies, as used and reported in [20]. These tests were primarily on subjects with relatively normal or elevated insulin sensitivity, as found in exercise based studies. They cover a range hyperinsulinaemic glycaemic clamp tests at both euglycaemia $(n=72)$ and hyperglycaemia $(n=5)$, for an insulin sensitive cohort.

The second data set consists of 146 hyperinsulinaemic euglycaemic clamps done on 73 subjects around a 3-month lifestyle intervention of varying intensity [27]. The subjects were normoglycaemic with elevated body mass index (BMI) levels of BMI $>30$. One test was done before the intervention and a second after to also assess the impact on insulin sensitivity. This is a normal to reduced insulin sensitivity cohort with modest increases in this metric after the intervention.

\section{$\underline{2.3 \text { PD Surface Fitting Method: }}$}

To fit the PD surface for the ND and MM cases, a grid search was used over physiological ranges of important variables. In this case, the values or equations for $P_{\text {end }}$ and $V_{G}$ are well reported and thus set to constants, as shown in the top portion of Table 1 and discussed or reviewed in $[20,30,38-40]$. Hence, the values of $P_{G}, \alpha_{G 2}, \alpha_{G}, S_{I}$ were allowed to vary. The physiological ranges for $\alpha_{G 2}, \alpha_{G}, S_{I}$ are based on an extensive literature search [41], model validation and sensitivity study [42], and are shown in the lower portion of Table 1.

Note that the variables $\alpha_{G 2}, \alpha_{G}$ can be set to zero in the ND model as well. Hence, there are two models that arise in this regard. The ND1 model sets $\alpha_{G 2}=0$ for all cases, considering only saturation on the insulin available for action at the receptor. In contrast, the ND2 model has non- 
zero values for both $\alpha_{G 2}$ and $\alpha_{G}$, considering saturation at both the insulin receptor and of the glucose available for uptake. The latter case matches the saturation dynamics used in the RM model. The MM case sets both to zero, as noted.

Table 1: Variable values used in ND and MM analyses

\begin{tabular}{|l|l|c|}
\hline Variable & Value & $\Delta$ increment \\
\hline \hline$P_{\text {end }}$ & $1.2 \mathrm{mmol} / \mathrm{L} / \mathrm{min}(=0$ for $\mathrm{MM})$ & - \\
\hline$V_{G}$ & $\begin{array}{l}V_{G}=0.19 * \text { Mass }(\mathrm{kg}) \rightarrow 13.3 \mathrm{~L}(\text { for } 70 \mathrm{~kg} \\
\text { indiv) }\end{array}$ & - \\
\hline$P_{G}$ & $1.0 \mathrm{e}-3-1.0 \mathrm{e}-1$ & $\Delta=1.0 \mathrm{e}-3$ \\
\hline$S_{I}$ & $1.0 \mathrm{e}-4-1.0 \mathrm{e}-2 \mathrm{~L} / \mathrm{mU} / \mathrm{min}$ & $\Delta=1.0 \mathrm{e}-4$ \\
\hline$\alpha_{G}$ & 0 and $1 / 20-1 / 80 \mathrm{~L} / \mathrm{mU} \quad(=0$ for $\mathrm{MM})$ & $\begin{array}{c}\Delta=+1.0 \text { in denominator } \\
{[1 / 20,1 / 21, \ldots, 1 / 80]}\end{array}$ \\
\hline$\alpha_{G 2}$ & 0 and $1 / 5-1 / 20 \mathrm{~L} / \mathrm{mmol} \quad(=0$ for $\mathrm{MM})$ & $\begin{array}{c}\Delta=+1.0 \text { in denominator } \\
{[1 / 5,1 / 6,1 / 7, \ldots, 1 / 20]}\end{array}$ \\
\hline
\end{tabular}

The overall approach is to first find values for the variables in the lower half of Table 1 for each model (ND1, ND2 and MM) that best fit the data from the 77 clamp studies. The second 146 clamp data set is used to evaluate these identified PD surfaces and models. Given that the main difference between these data sets is a general reduction in insulin sensitivity, the second set of data should be reasonably, although not optimally, fit by reducing insulin sensitivity alone. This hypothesis will be tested by re-fitting the data to these clamps by grid search over all variables, as well as only over the insulin sensitivity variable.

Thus, for each set of variables in the lower part of Table $1, \dot{G}=-P_{S S}$ is calculated from the model at the $\left(Q_{s s}, G_{s s}\right)$ from each clamp result. For example, the first data set thus creates 77 sets of $\left(Q_{s s}, G_{s s}\right) \rightarrow \dot{G}=-P_{s s}$ points for each combination of $\left(\alpha_{G 2}, \alpha_{G}, S_{I}\right)$. Importantly, this approach assumes that the steady state glucose infusion in the clamp $\left(P_{s S}\right)$ is the negative of the glucose rate of change $(\dot{G})$ that would occur without it. Hence, these terms represent the same value, with $P_{s s}$ for the clamp infusion to maintain euglycaemia and $\dot{G}$ for the equivalent endogenous balance 
change that would occur for the given glucose and insulin levels without it. The difference is in the sign with $P_{s s}$ positive and $\dot{G}$ negative in this usage.

This approach takes the several possible $\mathrm{z}=-P_{s s}$ values for a given $(\mathrm{x}, \mathrm{y})=\left(Q_{s s}, G_{s s}\right)$ pair and finds a single best value over the parameters in Table 1. It does so via fitting the data to minimum error metrics over these variables in a grid search looking for a best error fit. The result is that the identified surface thus has one $\mathrm{z}$ value for a given $(\mathrm{x}, \mathrm{y})$ pair with the identified parameters, found via the use of clinical euglycaemic clamp data. From fitting each model comparisons can be drawn to evaluate each models dynamics.

\subsection{Error Metrics:}

Overall, the ND2 model examines $9.76 \mathrm{e}+6$ combinations, the ND1 model $0.61 \mathrm{M}$, and the MM model 10,000 . The values decrease due to the reduction in non-zero variables in each case. Each combination results in an error for each clamp study examined (77 or 146 respectively), which are summarised in two forms:

1. RMS Error (RMS) - an average error metric, it rewards solutions that minimise error over all studies consistently without regard to distribution or the mode of the error distribution, which should ideally approach zero.

2. Frequency of Error Near Zero (FNZ) - number of errors within $+/-0.025$ of 0.000 error value or $\sim 5 \%$ of mean $\dot{G}$ observed in the clinical studies. This metric rewards solutions that have greater concentrations within the reported glycaemic clamp variability of $\sim 5 \%$ [30] around zero (0.0), regardless of the exact mode of the error or outliers due to variations in testing conditions or method across studies. 
Each error metric rewards a different quality of fit. RMS minimises outliers, without accounting for outlying clinical results or variation. AME rewards solutions that maximise "inliers" but not to a specific value. FNZ rewards "inlier" solutions within clinically observed variability for glycaemic clamps, allowing outliers for study variability and error. Ideally, each error metric would be minimised for the same variable set, or a very nearly identical set with similar minimum error values.

\subsection{RESULTS \& DISCUSSION}

\subsection{Model Identification and Analysis on First Clinical Data Set:}

Table 2 shows the results for identification over the 77 clamp studies from Arleth et al [20]. The minimum error set of model variables was the same over both error metrics in each case. Figures 1-4 show waterfall plots of the 3D PD surfaces around the glucose levels in the 77 clamp data for the MM, ND1, ND2 and RM models, respectively. Ideally, the waterfall lines of constant glucose level in these plots should pass through the clinical data at that same glucose level. The specific waterfall lines are plotted at (highest or top to lowest or bottom): [4.0, 4.5, 5.0, 5.5, 6.0] $\mathrm{mmol} / \mathrm{L}$ for the euglycaemic clamp data (left plot in Figure 1); and $[7.0,9.5,10.5,11.5] \mathrm{mmol} / \mathrm{L}$ for the hyperglycaemic clamp data (right plot in Figure 1). 
Table 2: Results (parameter values and errors for all models, where the best error values occur, in all cases, for the same parameter value sets.

\begin{tabular}{|c|c|}
\hline Model & Values and Error Performance \\
\hline MM & $\begin{array}{l}\alpha_{G}=\alpha_{G 2}=0 \mathrm{~L} / \mathrm{mU} \& \mathrm{~L} / \mathrm{mmol} \text { (as assumed) } \\
S_{I}=0.0001 \mathrm{~L} / \mathrm{mU} / \mathrm{min} ; \\
P_{G}=0.024 \\
\text { RMS }=0.29 \\
\text { FNZ }=24(\text { of } 77)\end{array}$ \\
\hline ND1 & $\begin{array}{l}\alpha_{G}=1 / 47 \mathrm{~L} / \mathrm{mU} ; \quad \alpha_{G 2}=0 \mathrm{~L} / \mathrm{mmol}, \\
S_{I}=0.0016 \mathrm{~L} / \mathrm{mU} / \mathrm{min} ; \\
P_{G}=0.006 \\
\text { RMS }=0.07 \\
\text { FNZ }=37 \text { (of } 77)\end{array}$ \\
\hline ND2 & $\begin{array}{l}\alpha_{G}=1 / 47 \mathrm{~L} / \mathrm{mU} ; \quad \alpha_{G 2}=1 / 6 \mathrm{~L} / \mathrm{mmol}, \\
S_{I}=0.0031 \mathrm{~L} / \mathrm{mU} / \mathrm{min} ; \\
P_{G}=0.006 \\
\text { RMS }=0.05 \\
\text { FNZ }=39(\text { of } 77)\end{array}$ \\
\hline $\mathbf{R M}$ & $\begin{array}{l}\text { Parameters as in Equations (1)-(7) - model fitted to this data set } \\
\text { RMS }=0.04 \\
\text { FNZ }=32 \text { (of 77) }\end{array}$ \\
\hline
\end{tabular}

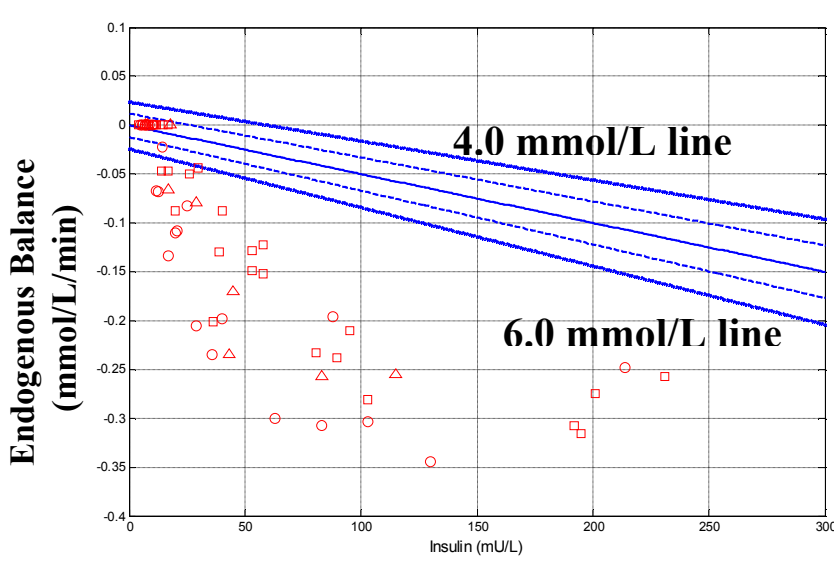

Insulin (mU/L)

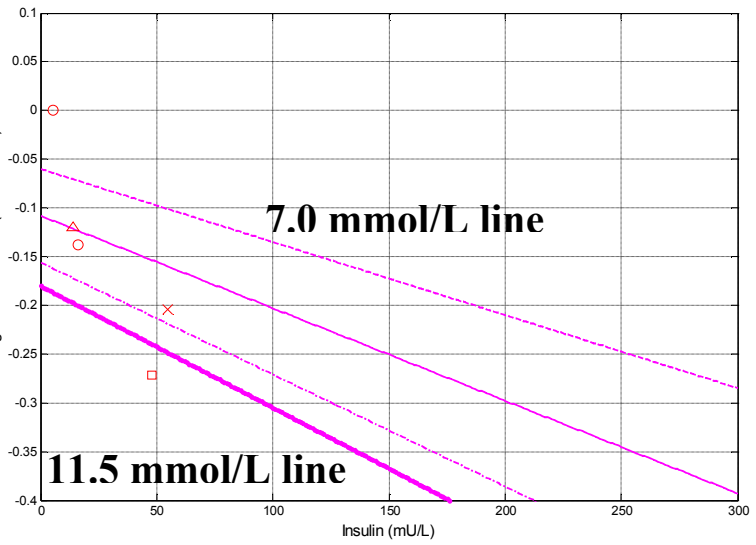

Insulin (mU/L)

Figure 1: Left: $M M$ waterfall with lines showing constant glucose at $G_{s S}=4.0,4.5,5.0,5.5$ and $6.0 \mathrm{mmol} / \mathrm{L}$. Clinical Studies: Squares: $G_{s s}=4-4.75 \mathrm{mmol} / \mathrm{L}$, Circles: $G_{S S}=4.75-5.25 \mathrm{mmol} / \mathrm{L}$ and Triangles: $G_{s S}=5.25-6.0 \mathrm{mmol} / \mathrm{L}$; Right: $\mathrm{MM}$ waterfall with lines showing constant glucose at $G_{s s}=7.5,9.5,11.5,12.5 \mathrm{mmol} / \mathrm{L}$. Clinical Studies: Circles: $G_{s s}=7.8 \mathrm{mmol} / \mathrm{L}$ studies, Triangles: $G_{s s}=9-10 \mathrm{mmol} / \mathrm{L}$, Squares: $G_{s s}=10-11 \mathrm{mmol} / \mathrm{L}$, and the $\mathrm{X}$ is $12-13 \mathrm{mmol} / \mathrm{L}$. The lowest and highest valued (top and bottom in plot) waterfall lines of constant glucose are labelled for clarity. 

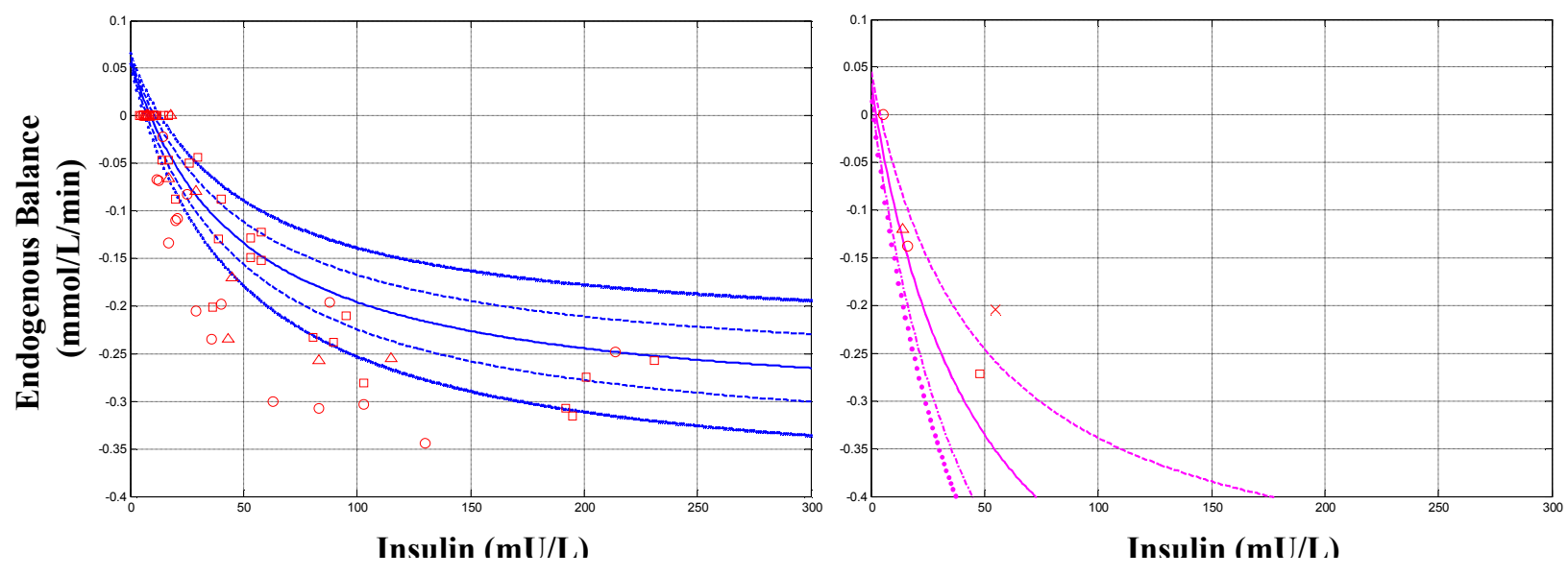

Figure 2: ND1 waterfall plots with data as defined in Figure 1 and on the same axes.
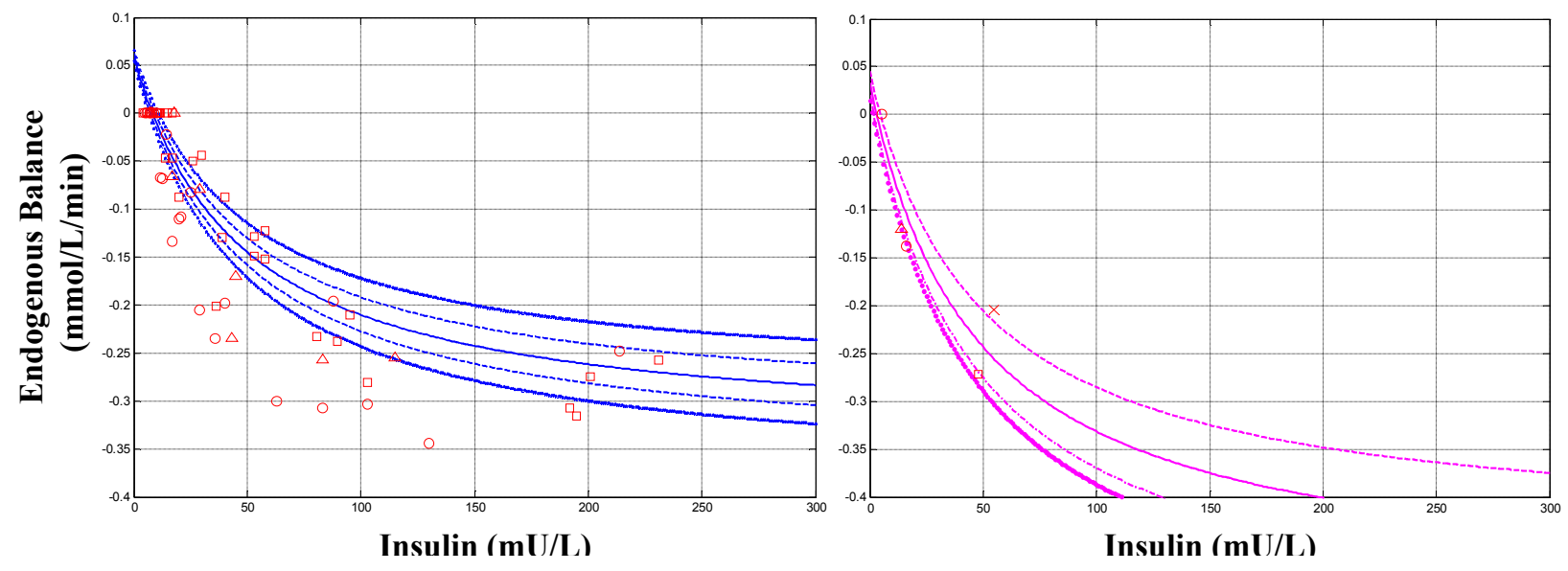

Figure 3: ND2 waterfall plots with data as defined in Figure 1 and on the same axes.
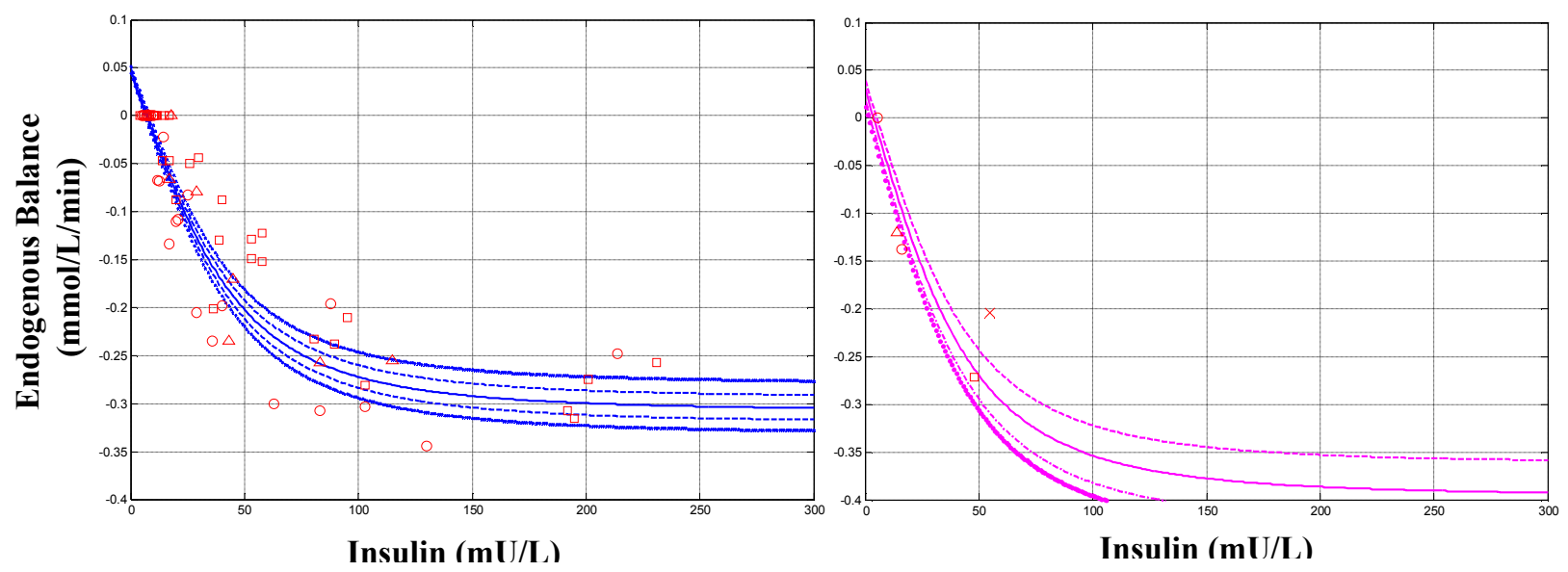

Figure 4: RM waterfall plots with data as defined in Figure 1 and on the same axes. The fit is essentially ideal as the saturation term of Equation (7) was defined to match this first set of 77 glycaemic clamp data. 
Five results can be obtained directly from Figures 1-4 and Table 2:

1. The MM identification can fit only one regime (euglycaemia or hyperglycaemia) well, while the same constants do not capture data from the other regime. As a result, errors are relatively much larger despite abnormally low insulin sensitivity values, where the value $S_{I}=1.0 \mathrm{e}-4$ in Table 2 is at the same level as a highly insulin resistant critical care patient [42-44]. Hence, the MM model is distinctly different, trying to adapt to its lack of dynamics by a lower $S_{I}$ value, matching reported under prediction when used in clamp studies $[45,46]$.

2. The ND1 and ND2 models provide qualitatively good fits with little difference between them and exactly the same parameters for $\alpha_{\mathrm{G}}$ and $\mathrm{P}_{\mathrm{G}}$. The added saturation dynamics in both models enable the waterfall lines of constant glucose to capture the data in each regime well, as these lines also reflect the clinically observed saturation dynamics as steady state insulin levels increase [47, 48].

3. The RM model provides the best fit to the clinical data due primarily to the very sharp insulin saturation curve provided by Equation (7), which was defined to match this data.

4. The ND1 and ND2 models have higher FNZ than the RM model, but also slightly greater RMS error, indicating that the ND1 and ND2 models capture the central data slightly better, but with greater outliers than the RM model.

5. The Michaelis-Menten glucose saturation level at $5 \mathrm{mmol} / \mathrm{L}$ in Equation (6) is close to equivalent to the $\alpha_{G 2}=1 / 6$ value in the ND2 model. Hence, given the small differences in error between the ND1 $\left(\alpha_{G 2}=0\right)$, ND2 and RM models for this data, it might be concluded that this second saturation of available glucose plays only a very minor role in this surface with respect to this data and might therefore be eliminated. 
These results are relatively novel in the field, which tends to examine models with respect to individual tests or outcomes, creating patient specific models and predictions. Hence, over a cohort of data, these results indicate that the ND1, ND2 and RM models perform similarly, while the MM model may not match more than a given (and thus patient specific) regime at a given set of model variables. Finally, there is some evidence that the saturation dynamics of insulin, at the receptor, may be more sharply non-linear than is best represented by the well-accepted Michaelis-Menton saturation model [49], as is illustrated schematically in Figure 5.

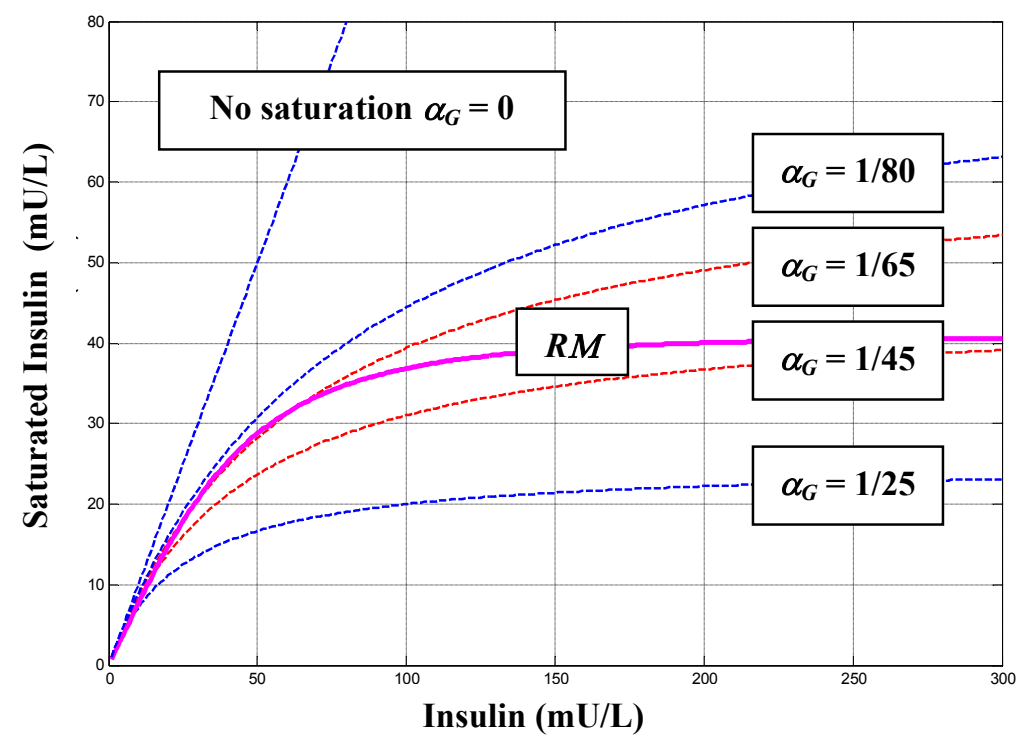

Figure 5: Comparison of insulin saturation curves, where the no saturation curve is the linear line seen in the MM case.

The sharper, highly non-linear saturation curve seen in Figure 5 also results in the closer lines of constant glucose in Figures 4. The softer Michaelis-Menten term only offers the wider glucose curves in Figures 2-3. Thus, the ND models provide a lesser fit to this clinical data, which is more sharply saturated, as seen at the euglycaemic glucose values in Figures 2-3. Note that while the ND2 model of Figure 3 is tighter with its second saturation, it is still not sharp enough to capture all the clinical data shown. This result thus suggests that there is a different saturation dynamic physiologically than is captured (fully) by Michaelis-Menten terms, at least over this range of clinical studies. 


\subsection{Model Prediction Based on Identification of the Second Clinical Data Set:}

Table 3 shows the results of identifying the MM, ND1 and ND2 models for the second data set. The RM model insulin sensitivity value of 1.0 for the first data set in Equation (7) was reduced, lowering the effect of insulin in Equation (6), to obtain a best match in this case, with all other parameters remaining the same. The ideal outcome is to see the best fit models have the same variable values $\left(P_{G}, \alpha_{G 2}, \alpha_{G}\right)$, excepting a lower insulin sensitivity $\left(S_{I}\right)$ value to match this less insulin sensitive cohort. Thus, a models PD surface might be validated in its ability to capture or predict this type of expected change in cohort. Therefore, Table 3 also shows the values from Table 2 for comparison to see if this hypothesis holds. If the variable values are the same or very similar, this result would validate both a given model's PD surface and, over all models, the general approach presented.

Table 3: Results (parameter values and errors) for $2^{\text {nd }}$ clinical data set of 146 glycaemic clamps, with first data set values from Table 2 for comparison. Brackets after $S_{I}$ show change in value (in \%) from $1^{\text {st }}$ data set for insulin sensitivity.

\begin{tabular}{|c|c|c|}
\hline Model & $2^{\text {nd }}$ Data Set Value (146 results) & $1^{\text {st }}$ Data Set Values (77 results) \\
\hline \multirow[t]{2}{*}{ MM } & $\begin{array}{l}\alpha_{G}=\alpha_{G 2}=0 \mathrm{~L} / \mathrm{mU} \& \mathrm{~L} / \mathrm{mmol} \\
S_{I}=0.0002 \mathrm{~L} / \mathrm{mU} / \mathrm{min}(+\mathbf{1 0 0} \%) \\
P_{G}=0.024\end{array}$ & $\begin{array}{l}\alpha_{G}=\alpha_{G 2}=0 \mathrm{~L} / \mathrm{mU} \& \mathrm{~L} / \mathrm{mmol} \\
S_{I}=0.0001 \mathrm{~L} / \mathrm{mU} / \mathrm{min} \\
P_{G}=0.024\end{array}$ \\
\hline & $\begin{array}{l}\text { RMS }=0.06 \\
F N Z=53(\text { of } 146)\end{array}$ & $\begin{array}{l}\text { RMS }=0.29 \\
F N Z=24(\text { of } 77)\end{array}$ \\
\hline \multirow[t]{2}{*}{ ND1 } & $\begin{array}{l}\alpha_{G}=1 / 48 \mathrm{~L} / \mathrm{mU} ; \alpha_{G 2}=0 \mathrm{~L} / \mathrm{mmol}, \\
S_{I}=0.0013 \mathrm{~L} / \mathrm{mU} / \mathrm{min}(\mathbf{- 1 9 \% )} \\
P_{G}=0.006\end{array}$ & $\begin{array}{l}\alpha_{G}=1 / 47 \mathrm{~L} / \mathrm{mU} ; \alpha_{G 2}=0 \mathrm{~L} / \mathrm{mmol}, \\
\mathrm{S}_{\mathrm{I}}=0.0016 \mathrm{~L} / \mathrm{mU} / \mathrm{min} ; \\
\mathrm{P}_{\mathrm{G}}=0.006\end{array}$ \\
\hline & $\begin{array}{l}\mathrm{RMS}=0.05 \\
\mathrm{FNZ}=54(\text { of } 146)\end{array}$ & $\begin{array}{l}\mathrm{RMS}=0.07 \\
\mathrm{FNZ}=37(\text { of } 77)\end{array}$ \\
\hline \multirow[t]{2}{*}{ ND2 } & $\begin{array}{l}\alpha_{G}=1 / 47 \mathrm{~L} / \mathrm{mU} ; \alpha_{G 2}=1 / 6 \mathrm{~L} / \mathrm{mmol}, \\
S_{I}=0.0023 \mathrm{~L} / \mathrm{mU} / \mathrm{min}(\mathbf{- 2 6 \% )} \\
P_{G}=0.006\end{array}$ & $\begin{array}{l}\alpha_{G}=1 / 47 \mathrm{~L} / \mathrm{mU} ; \quad \alpha_{G 2}=1 / 6 \mathrm{~L} / \mathrm{mmol}, \\
S_{I}=0.0031 \mathrm{~L} / \mathrm{mU} / \mathrm{min} \\
P_{C}=0.006\end{array}$ \\
\hline & $\begin{array}{l}\mathrm{RMS}=0.05 \\
\mathrm{FNZ}=60(\text { of } 146)\end{array}$ & $\begin{array}{l}\text { RMS }=0.05 \\
F N Z=39 \text { (of 77) }\end{array}$ \\
\hline \multirow[b]{2}{*}{$\mathbf{R M}$} & \begin{tabular}{|l} 
Insulin Sensitivity $=0.40$ (-60\%) \\
\end{tabular} & Insulin Sensitivity $=1.0$ \\
\hline & $\begin{array}{l}\mathrm{RMS}=0.05 \\
\mathrm{FNZ}=61(\text { of } 146)\end{array}$ & $\begin{array}{l}\mathrm{RMS}=0.04 \\
\mathrm{FNZ}=32(\text { of } 77)\end{array}$ \\
\hline
\end{tabular}


Examining Table 3 two results are readily clear:

1. The MM model does not accurately predict the change in cohort insulin sensitivity, despite lower error values and a higher FNZ as a percentage of the total data points compared to the first data set.

2. The ND1, ND2 and RM models all perform as ideally expected and with similar error and FNZ values. All three show the expected reduction in insulin sensitivity with identical values at the identified best fit for all other parameters.

Overall, the first result is not unexpected in terms of inaccurate prediction and underestimation of insulin sensitivity in resistant cohorts $[45,46]$. In addition, the MM values found for $S_{I}$ in both data sets is relatively very low, comparable to highly resistant critical care patients [42-44], which is not representative of the actual status of either clinical data set as neither set had a significant T2DM or severely insulin resistant portion [20, 27]. Such underestimation of insulin sensitivity is also not unknown with MM analysis [45, 50, 51].

Finally, the waterfall curves for this second data set are shown in Figure 6. These figures indicate that one reason the MM fits so well is that all the data points are in one euglycaemic range and at a relatively constant plasma insulin level. In contrast, the first data set values were spread over a wide range of plasma insulin levels and a very wide range of eu- and hyper- glycaemia. As a result, the MM fit to the second data set does not have to compromise, as it did for the first data set, between this spread of results and can offer, in fact, a better RMS error. More specifically, the second set does not as clearly show the saturation dynamics required to fit a range of such data that the first data set does. The overall result, is that the insulin sensitivity value for the MM case, all else equal, that fits the more insulin resistant second data set is higher than the value 
found for the less insulin resistant (more insulin sensitive) first data set - counter to clinical expectations and the clinical glycaemic clamp results.

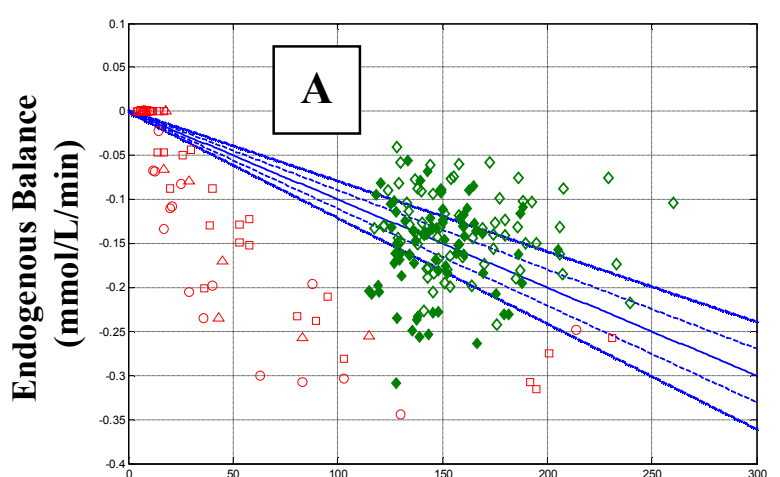

Insulin (mU/L)

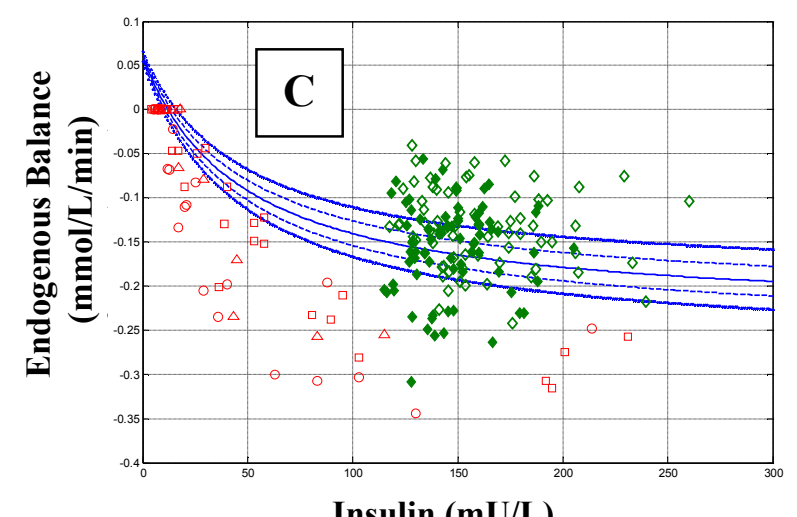

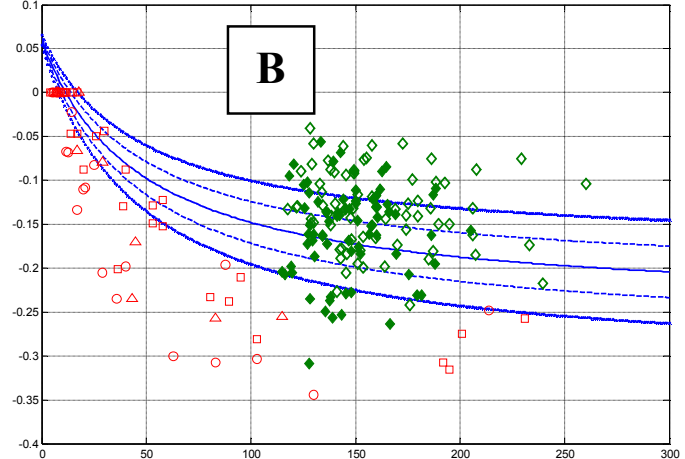

Insulin (mU/L)

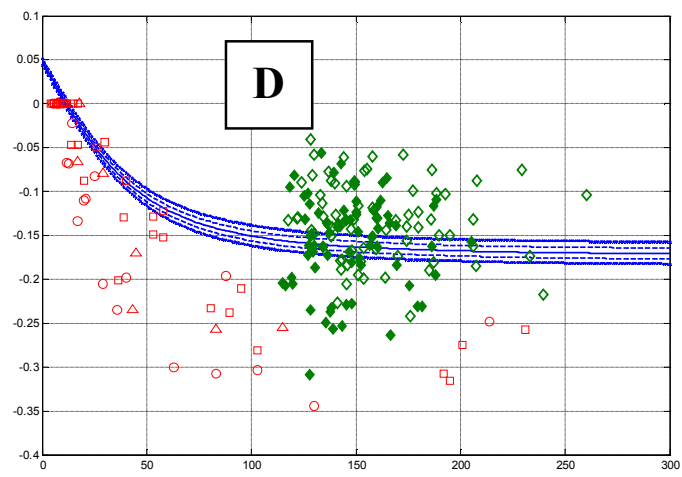

Insulin ( $\mathbf{m} \mathbf{U} / \mathbf{L})$

Figure 6: Waterfall plots with lines and data as defined in Figure 1 for the first data set of 77 glycaemic clamps, where the diamonds are the data for the second data set of 146 clamp studies (empty $=$ pre-intervention, less insulin sensitive and filled $=$ post-intervention). Plots for each model case are: (A) MM; (B) ND1; (C) ND2; (D) RM. The original clinical data from the first data set, per the Figure 1 definitions, are also shown for comparison.

Figure 6 also shows the first and second data set clamp results. The difference in insulin sensitivity between both groups is evident in that the endogenous balance change is smaller in magnitude (less negative) at a given insulin level than the first set. This difference indicates a smaller clearance for given steady state insulin levels, and thus lower insulin sensitivity for the second data set, in general. Note that this trend also holds for the pre- and post- intervention data indicated in these figures, where the post-intervention group is on average at a more negative (larger) endogenous balance change value for any given insulin level and thus have a higher 
insulin sensitivity than before the intervention, matching the results in the original study from which this data originated [27].

A final result from Figure 6, in this case, is that the tighter and sharper saturation curves resulting from the RM PD surface do not have the same spread over the clinical data that the ND1 and ND2 models have. Its spread is also narrower than the linear lines through this data of the MM case. Hence, it has a slightly larger RMS error in Table 3.

To further evaluate the issues with the MM surface, the PD surface was re-identified with a lower limit of 1.0e-3 for insulin sensitivity $\left(S_{I}\right)$ that is tighter than the constraints originally given in Table 1. However, the 1.0e-3 value is nearer the values reported in Table 3 for similarly derived ND1 and ND2 model structures. This constraint thus forces less underestimation of this parameter in favour of other model parameters. The results for are labelled the "Realistic" MM case versus the less constrained results labelled the "Best" case originally shown for the MM in Table 2. Both are shown in Table 4 for comparison.

With this constraint the values for $S_{I}$ and $S_{I}$ are both at the lower limits of 1.0e-3. As a result, the RMS error increases dramatically, as also evident in the resulting waterfall plots in Figure 7. In particular, the Realistic MM case captures a portion of the euglycaemic results for the first data set and the less numerous hyper-glycaemic results, where large errors result from those results that are missed by large margins in Figure 7. The FNZ also drops significantly, as would be expected. Finally, it is thus also evident that good, low error fits of the surface to either data set do not exist at variable values above these constraints, and that the trends between data sets will also not be matched, as seen previously in Table 3. 
Table 4: Results for a Realistic and Best case MM identification of PD surface to the first clinical data set results $(n=77)$, with \% changes in RMS and FNZ in brackets.

\begin{tabular}{|c|c|c|}
\hline Model & Realistic Case $1^{\text {st }}$ Data Set Values & Best Case $1^{\text {st }}$ Values from Table 2 \\
\hline MM & $\begin{array}{l}\alpha_{G}=\alpha_{G 2}=0 \mathrm{~L} / \mathrm{mU} \& \mathrm{~L} / \mathrm{mmol} \\
S_{I}=0.001 \mathrm{~L} / \mathrm{mU} / \mathrm{min} \text { (lower limit) } \\
P_{G}=0.001\end{array}$ & $\begin{array}{l}\alpha_{G}=\alpha_{G 2}=0 \mathrm{~L} / \mathrm{mU} \& \mathrm{~L} / \mathrm{mmol} \\
S_{I}=0.0001 \mathrm{~L} / \mathrm{mU} / \mathrm{min} \\
P_{G}=0.001\end{array}$ \\
\hline & $\begin{array}{ll}\text { RMS }=3.15 & (+\mathbf{1 1 0 0 \%}) \\
\mathrm{FNZ}=11(\text { of } 77) & (-\mathbf{4 5 \%})\end{array}$ & $\begin{array}{l}\mathrm{RMS}=0.29 \\
\mathrm{FNZ}=24(\text { of } 77)\end{array}$ \\
\hline
\end{tabular}

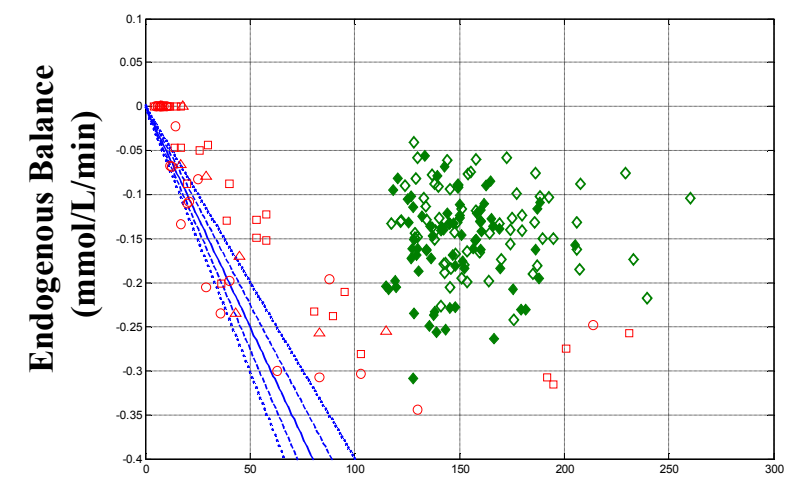

Insulin ( $\mathbf{m} \mathbf{U} / \mathbf{L})$

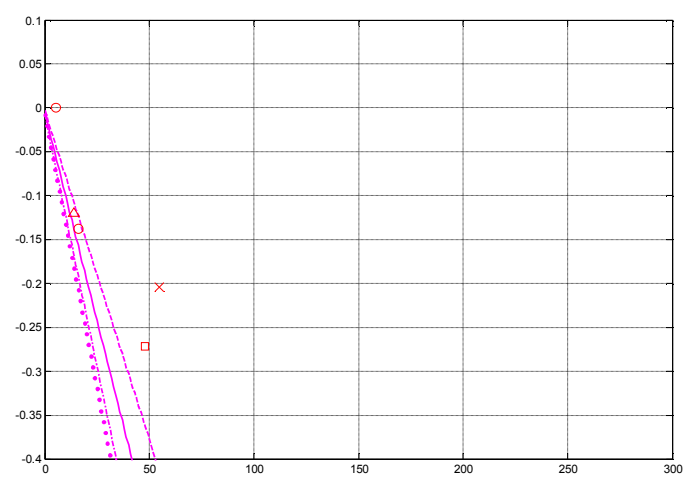

Insulin (mU/L)

Figure 7: Waterfall plots for "Realistic" $M M$ case for euglycaemia results (Left) and hyperglycaemic results (Right). All lines and clinical data are as defined in Figures 1 and 6 for the two clinical data sets.

\subsection{Summary and $3 D$ results:}

Overall, these results also show how this PD surface analysis can clearly differentiate models that might not appear so different in other examinations. To further clarify these differences the 3D PD surfaces are shown in Figures 8 for each model case with the data points from the first data set. Note that the figures do not show the detail or level of accuracy of Figures 1-4, 6 and 7. However, they clearly show differences due to different saturation dynamics along the glucose and insulin axes ( $\mathrm{x}$ and $\mathrm{y})$, where the vertical ( $\mathrm{z}$ ) axis is the change in endogenous balance. 

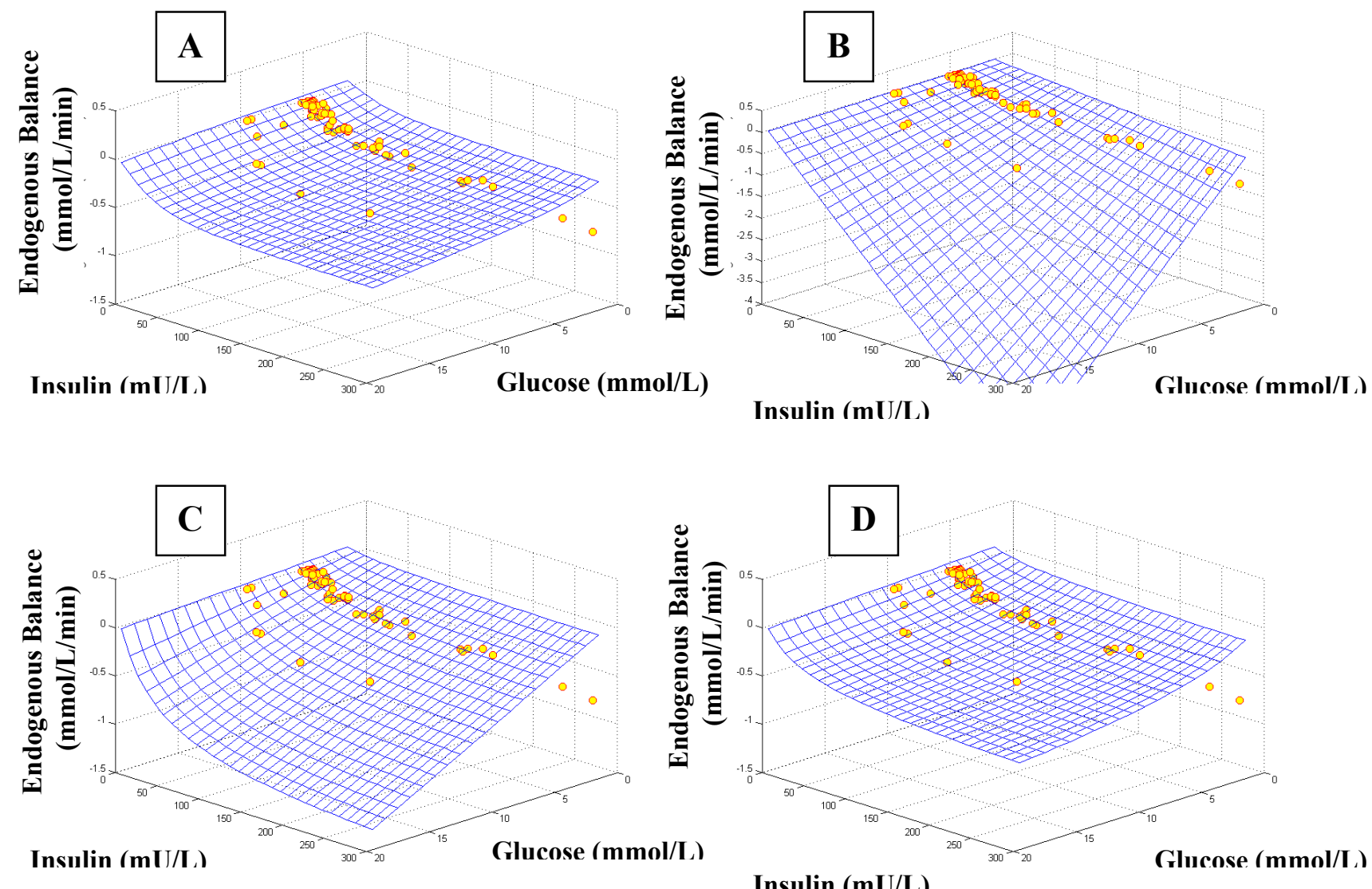

Insulin (mU/L)

Figure 8: 3D PD surface plots optimised for data set 1 with data points shown as filled circles on the surfaces. (A): RM; (B): MM for realistic case with z-axis 3 times larger than other subplots; (C): ND1 and (D): ND2. Note that the MM case with best parameters and very low SI value for this data set has the same shape, but lower linear slopes along the glucose and insulin axes. The difference in sharpness and number of saturation dynamics is clearer in this view than in the waterfall plots of Figures 1-4, 6 and 7.

\subsection{Study Limitations:}

All models and model-based analyses are estimates of an exact reality and thus have limitations. In this study, neither the Michaelis-Menten nor the custom defined RM insulin saturation dynamic of Equation (7) appear to be fully generalisable over all the clinical data employed. Neither dynamic fully captures the spread or specific sharpness of the saturation over steady state insulin values seen in Figures 2-4, 6 and 7. Where the RM case captures the first data set well, for which it was defined, it was too narrow or tight for the second set. The opposite appears to hold somewhat true for the Michaelis-Menten dynamics used in the ND1 and ND2 models. It 
is thus likely that some further dynamic model might need to be derived for this particular case [49], or a more exact/complex glucose-insulin PD interaction model defined $[21,52,53]$ if this type of model is to better account for the clinical data shown.

In contrast, there is also significant variability in exactly how a given hyperinsulinaemic clamp is delivered, including the insulin dosage and timing in particular. Thus, different groups may obtain different results for a given "same" individual, particularly as insulin dosage varies [47]. In addition, different methods for adjusting the glucose infusion to maintain glycaemia at a set level (eu- or hyper- glycaemic) can also introduce variability beyond the 3-4\% C.V. reported for the clamp [30]. Hence, it could be argued that some measurable error should be observed between the metabolic dynamics of a fixed model and those from a large series of hyperglycaemic and/or euglycaemic clamp studies. This last point might be more important if these clinical data points are obtained from different clinical groups.

A final limitation in this study is that the second data set contains only euglycaemic clamps ranging primarily from $4.0-5.5 \mathrm{mmol} / \mathrm{L}$. They also used the same protocol for each clamp, which ensures relatively consistent insulin levels further concentrating the data in one portion of the waterfall plots and PD surfaces. Thus, while they are an obviously lower insulin sensitivity group cohort than those in the first data set, the model fit to this group may be different due to its concentration in one part of the surface. However, it should also be noted that the ND1, ND2 and RM models capture this difference directly and with only an appropriate scaling of insulin sensitivity. In contrast, the MM is unable to show the same appropriate scaling due to its lack of saturation dynamics, and not as a result of where the data are located. 
It should also be noted that the MM was not designed for this type of supra-physiological testing. Its primary use has been in determining insulin sensitivity at lower insulin and glucose doses in FSIVGTTs (frequently sampled intravenous glucose tolerance tests) and similar tests [31, 45, 54]. Hence, at the more supra-physiological levels seen in the clamp this model may be less well suited than more non-linear models, although some studies have shown a measure of equivalence between the MM enabled FSIVGTT and the clamp [32].

Finally, it is important to note that the PD analysis approach presented should not be seen as a replacement for fitting or prediction validations on clinical data using patient-specific models. This approach is limited to examining the overall dynamics of a model structure, and the PD surface in particular. While this PD surface will define the trend of predictions, as shown here, it is not a replacement for patient-specific prediction, particularly if the primary or eventual intent is to apply the model in a clinical testing or control scenario. It is thus a tool primarily for verifying or validating an overall model structure and the dynamics it includes, rather than a validation unto itself.

\subsection{CONCLUSIONS}

A new PD surface oriented approach to analysing and validating PK and PD system models has been presented in the context of metabolic systems models. Two non-linear, physiologically representative dynamic models (ND1, ND2), a receptor-based (RM) model, and the well-known Minimal Model (MM) were examined. The ND and RM models provide similar dynamics with significant differences in the exact modeling method and specific physiological saturation dynamics and their definitions that are included. In contrast, the MM is not physiologically 
representative enough to provide a 3D surface that captures the clinical data outside specific insulin and glucose ranges, illustrating the difficulty in using this model for predictive glycaemic control. The reported under-prediction of insulin sensitivity by the MM is also clearly evident. Comparing ND1 and ND2 shows a potential need to include both saturation terms used in the ND2 model due to trade offs between insulin sensitivity and the second saturation term that occur in the ND1. The RM model would benefit from validation on additional data in future work.

Overall, the method clearly highlights the role and impact of the specific fundamental model dynamics. Analysing a model over an entire PD surface, given available clinical experimental data, can provide a level of analysis that using one or a few studies will not show. Thus, the MM can match limited data points, but not a series of data points over a wide range of the PD surface. As a result, this approach, particularly used as shown here to capture known trends in data, can provide both analytical insight, as well as a validation of the fundamental model dynamics. Hence, unnecessary dynamics can be excluded, improving identifiability or computational requirements, while missing dynamics may be clearly highlighted. Finally, the overall approach is readily generalised to similar system models or physiology. 


\section{REFERENCES}

1. Wild S, Roglic G, Green A, Sicree R, King H: Global prevalence of diabetes: estimates for the year 2000 and projections for 2030. Diabetes Care 2004, 27(5):1047-1053.

2. Wild SH, Forouhi NG: What is the scale of the future diabetes epidemic, and how certain are we about it? Diabetologia 2007.

3. Hossain P, Kawar B, El Nahas M: Obesity and diabetes in the developing world--a growing challenge. $N$ Engl $J$ Med 2007, 356(3):213-215.

4. ADA: Economic consequences of diabetes mellitus in the U.S. in 1997. American Diabetes Association. Diabetes Care 1998, 21(2):296-309.

5. Nichols GA, Brown JB: Higher medical care costs accompany impaired fasting glucose. Diabetes Care 2005, 28(9):2223-2229.

6. Olshansky SJ, Passaro DJ, Hershow RC, Layden J, Carnes BA, Brody J, Hayflick L, Butler RN, Allison DB, Ludwig DS: A potential decline in life expectancy in the United States in the 21st century. N Engl J Med 2005, 352(11):1138-1145.

7. Hogan P, Dall T, Nikolov P: Economic costs of diabetes in the US in 2002. Diabetes Care 2003, 26(3):917-932.

8. ADA: The prevention or delay of type 2 diabetes. Diabetes Care 2002, 25(4):742-749.

9. ADA: Standards of medical care in diabetes-2006. Diabetes Care 2006, 29:S4-S42.

10. Mainous AG, Diaz VA, Saxena S, Baker R, Everett CJ, Koopman RJ, Majeed A: Diabetes management in the USA and England: comparative analysis of national surveys. Journal of the Royal Society of Medicine 2006, 99(9):463-469.

11. Krinsley JS: Effect of an intensive glucose management protocol on the mortality of critically ill adult patients. Mayo Clin Proc 2004, 79(8):992-1000.

12. Van den Berghe G, Wouters P, Weekers F, Verwaest C, Bruyninckx F, Schetz M, Vlasselaers D, Ferdinande P, Lauwers P, Bouillon R: Intensive insulin therapy in the critically ill patients. $N$ Engl J Med 2001, 345(19):1359-1367.

13. Chase JG, Shaw G, Le Compte A, Lonergan T, Willacy M, Wong XW, Lin J, Lotz T, Lee D, Hann C: Implementation and evaluation of the SPRINT protocol for tight glycaemic control in critically ill patients: a clinical practice change. Crit Care 2008, 12(2):R49.

14. Krinsley J: Perioperative glucose control. Curr Opin Anaesthesiol 2006, 19(2):111-116.

15. Van den Berghe G, Wouters PJ, Kesteloot K, Hilleman DE: Analysis of healthcare resource utilization with intensive insulin therapy in critically ill patients. Crit Care Med 2006, 34(3):612-616.

16. Krinsley JS, Jones RL: Cost analysis of intensive glycemic control in critically ill adult patients. Chest 2006, 129(3):644-650.

17. Egi M, Bellomo R, Stachowski E, French CJ, Hart G: Variability of blood glucose concentration and short-term mortality in critically ill patients. Anesthesiology 2006, 105(2):244-252.

18. Chase JG, Hann CE, Shaw GM, Wong XW, Lin J, Lotz T, Le Compte AJ, Lonergan T: An Overview of Glycemic Control in Critical Care - Relating Performance and Clinical Results. Journal of Diabetes Science and Technology 2007, 1(1):82-91.

19. Carson ER, Cobelli C: Modelling methodology for physiology and medicine. San Diego: Academic Press; 2001.

20. Arleth T, Andreassen S, Federici MO, Benedetti MM: A model of the endogenous glucose balance incorporating the characteristics of glucose transporters. Comput Methods Programs Biomed 2000, 62(3):219-234.

21. Hovorka R, Canonico V, Chassin LJ, Haueter U, Massi-Benedetti M, Federici MO, Pieber TR, Schaller HC, Schaupp L, Vering T et al: Nonlinear model predictive control 
of glucose concentration in subjects with type 1 diabetes. Physiological Measurement 2004, 25(4):905-920.

22. Plank J, Blaha J, Cordingley J, Wilinska ME, Chassin LJ, Morgan C, Squire S, Haluzik $\mathrm{M}$, Kremen J, Svacina S et al: Multicentric, randomized, controlled trial to evaluate blood glucose control by the model predictive control algorithm versus routine glucose management protocols in intensive care unit patients. Diabetes Care 2006, 29(2):271-276.

23. Wong XW, Singh-Levett I, Hollingsworth LJ, Shaw GM, Hann CE, Lotz T, Lin J, Wong OS, Chase JG: A novel, model-based insulin and nutrition delivery controller for glycemic regulation in critically ill patients. Diabetes Technol Ther 2006, 8(2):174190.

24. Wong J, Chase JG, Hann CE, Lotz TF, Lin J, Le Compte A, Shaw GM: Development of a Clinical Type 1 Diabetes Metabolic System Model and in Silico Simulation Tool. Journal of Diabetes Science and Technology 2008, 2(3):425-435.

25. Lotz TF, Chase JG, McAuley KA, Lee DS, Lin J, Hann CE, Mann JI: Transient and steady-state euglycemic clamp validation of a model for glycemic control and insulin sensitivity testing. Diabetes Technol Ther 2006, 8(3):338-346.

26. Pielmeier U, Chase J, Andreassen S, Haure P, Nielsen B, Shaw G: Prediction Validation of Two Glycaemic Control Models in Critical Care. In: 17th IFAC World Congress (IFAC WC2008): July 6-11 2008; Seoul, Korea; 2008: 8074-8079.

27. McAuley KA, Williams SM, Mann JI, Goulding A, Chisholm A, Wilson N, Story G, McLay RT, Harper MJ, Jones IE: Intensive lifestyle changes are necessary to improve insulin sensitivity: a randomized controlled trial. Diabetes Care 2002, 25(3):445-452.

28. Wong XW, Chase JG, Shaw GM, Hann CE, Lotz T, Lin J, Singh-Levett I, Hollingsworth LJ, Wong OS, Andreassen S: Model predictive glycaemic regulation in critical illness using insulin and nutrition input: a pilot study. Med Eng Phys 2006, 28(7):665-681.

29. Blakemore A, Wang S, LeCompte A, Wong X, Shaw G, Lin J, Lotz T, Hann C, Chase J: Model-based Insulin Sensitivity as a Sepsis Diagnostic in Critical Care. Journal of Diabetes Science and Technology (JoDST) 2008, 2(3):468-477.

30. Lotz TF, Chase JG, McAuley KA, Shaw GM, Wong XW, Lin J, Lecompte A, Hann CE, Mann JI: Monte Carlo analysis of a new model-based method for insulin sensitivity testing. Comput Methods Programs Biomed 2008, 89(3):215-225.

31. Bergman RN, Finegood DT, Ader M: Assessment of insulin sensitivity in vivo. Endocr Rev 1985, 6(1):45-86.

32. Bergman RN, Prager R, Volund A, Olefsky JM: Equivalence of the insulin sensitivity index in man derived by the minimal model method and the euglycemic glucose clamp. J Clin Invest 1987, 79(3):790-800.

33. Pacini G, Bergman RN: MINMOD: a computer program to calculate insulin sensitivity and pancreatic responsivity from the frequently sampled intravenous glucose tolerance test. Comput Methods Programs Biomed 1986, 23(2):113-122.

34. Vicini P, Caumo A, Cobelli C: The hot IVGTT two-compartment minimal model: indexes of glucose effectiveness and insulin sensitivity. Am $J$ Physiol 1997, 273(5 Pt 1):E1024-1032.

35. Vicini P, Caumo A, Cobelli C: Glucose effectiveness and insulin sensitivity from the minimal models: consequences of undermodeling assessed by Monte Carlo simulation. IEEE Trans Biomed Eng 1999, 46(2):130-137.

36. Dalla Man C, Caumo A, Cobelli C: The oral glucose minimal model: Estimation of insulin sensitivity from a meal test. Ieee Transactions on Biomedical Engineering 2002, 49(5):419-429. 
37. Dalla Man C, Campioni M, Polonsky KS, Basu R, Rizza RA, Toffolo G, Cobelli C: Twohour seven-sample oral glucose tolerance test and meal protocol: minimal model assessment of beta-cell responsivity and insulin sensitivity in nondiabetic individuals. Diabetes 2005, 54(11):3265-3273.

38. Chambrier C, Laville M, Rhzioual Berrada K, Odeon M, Bouletreau P, Beylot M: Insulin sensitivity of glucose and fat metabolism in severe sepsis. Clin Sci (Lond) 2000, 99(4):321-328.

39. DeFronzo RA, Tobin JD, Andres R: Glucose clamp technique: a method for quantifying insulin secretion and resistance. Am J Physiol 1979, 237(3):E214-223.

40. Lotz T, Chase JG, Lin J, Wong XW, Hann CE, McAuley KA, Andreassen S: IntegralBased Identification of a Physiological Insulin and Glucose Model on Euglycaemic Clamp Trials. In: 14th IFAC Symposium on System Identification (SYSID 2006): March 29-31 2006; Newcastle, Australia: IFAC; 2006: 463-468.

41. Doran CV: Modelling and Control of Hyperglycemia in Critical Care Patients. Masters of Engineering (ME). Christchurch, New Zealand: University of Canterbury; 2004.

42. Hann CE, Chase JG, Lin J, Lotz T, Doran CV, Shaw GM: Integral-based parameter identification for long-term dynamic verification of a glucose-insulin system model. Comput Methods Programs Biomed 2005, 77(3):259-270.

43. Lin J, Lee, DS, Chase, JG, Hann, CE, Lotz, T and Wong, XW: Stochastic Modelling of Insulin Sensitivity Variability in Critical Care. Biomedical Signal Processing \& Control 2006, 1:229-242.

44. Lin J, Lee D, Chase JG, Shaw GM, Le Compte A, Lotz T, Wong J, Lonergan T, Hann $\mathrm{CE}$ : Stochastic modelling of insulin sensitivity and adaptive glycemic control for critical care. Comput Methods Programs Biomed 2008, 89(2):141-152.

45. Cobelli C, Caumo A, Omenetto M: Minimal model SG overestimation and SI underestimation: improved accuracy by a Bayesian two-compartment model. $\mathrm{Am} \mathrm{J}$ Physiol 1999, 277(3 Pt 1):E481-488.

46. Pacini G, Mari A: Methods for clinical assessment of insulin sensitivity and beta-cell function. Best Pract Res Clin Endocrinol Metab 2003, 17(3):305-322.

47. Prigeon RL, Roder ME, Porte D, Jr., Kahn SE: The effect of insulin dose on the measurement of insulin sensitivity by the minimal model technique. Evidence for saturable insulin transport in humans. $J$ Clin Invest 1996, 97(2):501-507.

48. Natali A, Gastaldelli A, Camastra S, Sironi AM, Toschi E, Masoni A, Ferrannini E, Mari A: Dose-response characteristics of insulin action on glucose metabolism: a nonsteady-state approach. Am J Physiol Endocrinol Metab 2000, 278(5):E794-801.

49. Andreassen S, Pielmeier U, Chase J: Receptor-based Models of Insulin Saturation Dynamics. In: The Sixth IASTED International Conference on Biomedical Engineering (BIOMED 2008): Feb 13-15 2008; Innsbruck, Austria; 2008: 4-pages.

50. Cobelli C, Bettini F, Caumo A, Quon MJ: Overestimation of minimal model glucose effectiveness in presence of insulin response is due to undermodeling. Am J Physiol 1998, 275(6 Pt 1):E1031-1036.

51. Toffolo G, Cobelli $\mathrm{C}$ : The hot IVGTT two-compartment minimal model: an improved version. Am J Physiol Endocrinol Metab 2003, 284(2):E317-321.

52. Hovorka R, Shojaee-Moradie F, Carroll PV, Chassin LJ, Gowrie IJ, Jackson NC, Tudor RS, Umpleby AM, Jones RH: Partitioning glucose distribution/transport, disposal, and endogenous production during IVGTT. Am J Physiol Endocrinol Metab 2002, 282(5):E992-1007.

53. Hovorka R, Chassin LJ, Wilinska ME: Virtual type 1 diabetic treated by CSII: Model description. In: WC2003: 24-29 Aug 2003; Sydney, Australia; 2003. 
54. Toffolo G, De Grandi F, Cobelli C: Estimation of beta-cell sensitivity from intravenous glucose tolerance test $\mathrm{C}$-peptide data. Knowledge of the kinetics avoids errors in modeling the secretion. Diabetes 1995, 44(7):845-854. 